\title{
Stimulation of Biomethane Productivity in Anaerobic Digestion Using Electro-Conductive Carbon-Nanotube Hollow-Fiber Media
}

\author{
Seongmin Yang ${ }^{1}$, Seungyeob Han ${ }^{1}$, Yeo-Myeong Yun ${ }^{2, *}$ and Seoktae Kang ${ }^{1, * \mathbb{D}}$ \\ 1 Department of Civil and Environmental Engineering, KAIST, 291 Daehak-ro, Yuseong-gu, \\ Daejeon 34141, Korea; yssm0303@kaist.ac.kr (S.Y.); sksm91@gmail.com (S.H.) \\ 2 Department of Environmental Engineering, Chungbuk National University, Cheongju 28644, Korea \\ * Correspondence: ymyun@chungbuk.ac.kr (Y.-M.Y.); stkang@kaist.ac.kr (S.K.); Tel.: +82-43-261-2466 (Y.-M.Y.); \\ +82-42-350-3635 (S.K.); Fax: +82-43-264-2465 (Y.-M.Y.); +82-42-350-3610 (S.K.)
}

check for updates

Citation: Yang, S.; Han, S.; Yun,

Y.-M.; Kang, S. Stimulation of

Biomethane Productivity in Anaerobic Digestion Using ElectroConductive Carbon-Nanotube Hollow-Fiber Media. Minerals 2021, 11, 179. https://doi.org/10.3390/ $\min 11020179$

Academic Editor: Carolina Cruz Viggi Received: 13 January 2021

Accepted: 4 February 2021

Published: 8 February 2021

Publisher's Note: MDPI stays neutral with regard to jurisdictional claims in published maps and institutional affiliations.

Copyright: (C) 2021 by the authors. Licensee MDPI, Basel, Switzerland. This article is an open access article distributed under the terms and conditions of the Creative Commons Attribution (CC BY) license (https:// creativecommons.org/licenses/by/ $4.0 /)$.

\begin{abstract}
The production of biogas was promoted via direct interspecies electron transfer (DIET) by employing electro-conductive carbon-nanotube hollow-fiber media (CHM) in anaerobic digestion. Experimental results showed a positive effect of $\mathrm{CHM}$ presence on $\mathrm{CH}_{4}$ productivity with $34 \%$ higher $\mathrm{CH}_{4}$ production rate than that of in the presence of non-electroconductive polymeric hollow fiber media. An increased $\mathrm{CH}_{4}$ production rate was due to the shift in the microbiome with more abundant Pelobacter (10.0\%), Geobacter (6.9\%), and Methanosaeta (15.7\%), which play key roles in promoting $\mathrm{CH}_{4}$ production via syntrophic metabolism associated with DIET. Microscopic morphology analysis, using confocal laser scanning microscopy and scanning electron microscopy, exhibited that several living cells were attached with electro-conductive pili on the CHM surface, thereby facilitated electron transport between microbial cells.
\end{abstract}

Keywords: anaerobic digestion; carbon nanotube hollow-fiber media; direct interspecies electron transfer; Pelobacter; Methanosaeta

\section{Introduction}

Increasing global concern regarding waste management and energy security is driving the technological development related to the waste-to-energy concept. Anaerobic digestion (AD) is a well-established and mature technology that not only stabilizes organic wastes, but also produces biogas, which is a mixture of $\mathrm{CH}_{4}$ and $\mathrm{CO}_{2}$ [1,2]. Currently, 132,000 AD plants are utilized globally, and the biogas market size is projected to reach USD 32 billion by 2027 [3].

Anaerobic digestion is strongly dependent on the mutualistic and syntrophic interactions of the anaerobic microbiome to break down organic compounds via a series of biological processes, i.e., hydrolysis, acidogenesis, acetogenesis, and methanogenesis [4,5]. During hydrolysis, large organic molecules are first decomposed to soluble monomers by hydrolytic bacteria and are subsequently converted into acetic acid, $\mathrm{H}_{2}$, and $\mathrm{CO}_{2}$ during acidogenesis and acetogenesis. Finally, methanogenic archaea produce $\mathrm{CH}_{4}$ from acetic acid and $\mathrm{H}_{2}$.

Process instability due to the complex AD food web is a common operational issue hampering the AD technology from being widely adopted. A major factor affecting the performance and stability of AD systems is the relatively slow syntrophic metabolism between syntrophic bacteria (i.e., $\mathrm{H}_{2}$ production) and methanogenic archaea (i.e., $\mathrm{H}_{2}$ consumption). It is believed that the main interaction between these two types of microorganisms during AD is based on interspecies electron transfer (IET), in which hydrogen serves as an electron carrier [6,7].

Syntrophic bacteria degrade a variety of organic compounds and produce acetate and $\mathrm{H}_{2}$ through energetically unfavorable reactions. To make this reaction thermodynamically 
exergonic, methanogenic archaea always play a crucial role in regulating the $\mathrm{H}_{2}$ level. The fluctuation of the $\mathrm{H}_{2}$ partial pressure is critical for the syntrophic relation of the IET. This fluctuation often causes accumulation of organic acids, and as a result, the reactor can fail. [8,9].

Recent studies have introduced direct interspecies electron transfer (DIET) from cell to cell between electroactive bacteria and methanogenic archaea partners through electrically conductive pili and c-type cytochrome $[10,11]$. DIET is more efficient than IET because it does not require multiple enzymatic steps for producing $\mathrm{H}_{2}$ as an electron carrier and generation and diffusion of metabolites [12].

Several studies have further demonstrated that the $\mathrm{CH}_{4}$ production improvement in $\mathrm{AD}$ is amended with the addition of a variety of conductive materials that can serve as electrical conduits to facilitate DIET. The vast majority of DIET studies have supplemented carbon-based conductive materials of various types of substrates in AD [13]; however, there is no clear evidence of DIET in the mixed culture. Furthermore, these supplements are easily washed out during continuous operation [6]. Carbon-nanotube hollow-fiber media (CHM) provide a large surface area where multiple microorganisms can be immobilized. In addition, CHM have increased stability and electrical conductivity; hence, they are suitable as conductive material in AD [14,15].

In this study, we evaluated the effect of CHM on biogas productivity during continuous AD. Reactor 1 (R1) included CHM; Reactor 2 (R2)-used as control-included polymeric hollow-fiber media (PHM), i.e., insulative material with similar biomass retention properties. To visualize the influence of $\mathrm{CHM}$ on $\mathrm{AD}$, we utilized scanning electron microscopy (SEM) and confocal laser scanning microscopy (CLSM). Both R1 and R2 microbiomes were further analyzed via 16S rRNA-based next-generation sequencing (NGS) to reveal more comprehensive insights into the microbial behavior related to DIET.

\section{Materials and Methods}

\subsection{Preparation of Seed Sludge and Feedstock}

The seed sludge was collected from an up-flow anaerobic sludge blanket at a local brewery wastewater treatment plant located in Cheong-Ju, Korea. This inoculum was acclimated at $35^{\circ} \mathrm{C}$ under anaerobic conditions for 14 days to remove residual compounds. The total solids (TS), volatile solids (VS), alkalinity, and $\mathrm{pH}$ of the seed sludge were $7.2 \mathrm{~g} / \mathrm{L}$, $3.6 \mathrm{~g} / \mathrm{L}, 3.3 \mathrm{~g} \mathrm{CaCO}_{3} / \mathrm{L}$, and 7.0, respectively.

After the successful preparation of the microbe growth medium, the BA medium was prepared using the following (per liter): $\mathrm{NaHCO}_{3}, 4.12 \mathrm{~g}$; yeast extract, $0.56 \mathrm{~g} ; \mathrm{KH}_{2} \mathrm{PO}_{4}$, $219.4 \mathrm{mg} ; \mathrm{NH}_{4} \mathrm{Cl}, 955.4 \mathrm{mg} ; \mathrm{FeCl}_{2}, 37.8 \mathrm{mg}$; resazurin solution, $1 \mathrm{~mL}$; and trace element solution, $0.1 \mathrm{~mL}$. The resazurin solution composition was as follows: resazurin, $0.5 \mathrm{mg} / \mathrm{L}$; $\mathrm{MgCl}_{2} \cdot 6 \mathrm{H}_{2} \mathrm{O}, 10 \mathrm{mg} / \mathrm{L}$; and $\mathrm{CaCl}_{2}, 5 \mathrm{mg} / \mathrm{L}$. The composition of trace element solution comprised (per liter) the following: $\mathrm{Na}_{2} \mathrm{MoO}_{4} \cdot 4 \mathrm{H}_{2} \mathrm{O}, 0.1 \mathrm{mg} ; \mathrm{MgCl}_{2} \cdot 6 \mathrm{H}_{2} \mathrm{O}, 1000 \mathrm{mg} ; \mathrm{CaCl}_{2}$, $750 \mathrm{mg} ; \mathrm{H}_{3} \mathrm{BO}_{3}, 0.5 \mathrm{mg} ; \mathrm{MnCl}_{2} \cdot 4 \mathrm{H}_{2} \mathrm{O}, 5 \mathrm{mg} ; \mathrm{ZnCl}_{2}, 0.5 \mathrm{mg} ; \mathrm{CuCl}_{2}, 0.3 \mathrm{mg} ; \mathrm{NiCl}_{2} \cdot 6 \mathrm{H}_{2} \mathrm{O}$, $0.5 \mathrm{mg} ; \mathrm{CoCl}_{2} \cdot 2 \mathrm{H}_{2} \mathrm{O}, 5 \mathrm{mg} ; \mathrm{Na}_{2} \mathrm{SeO}_{3}, 0.5 \mathrm{mg}$; EDTA, $5 \mathrm{mg}$; and $\mathrm{AlCl}_{3}, 0.5 \mathrm{mg}$. Ethanol was used as a carbon source.

\subsection{Preparation of Carbon-Nanotube Hollow-Fiber Media and Polymeric Hollow Fiber Media}

Carbon-nanotube hollow-fiber media were fabricated using the wet spinning method with thermal calcination [16]. Multi-wall carbon nanotubes (MWCNTs; Cheap Tubes Inc., Cambridgeport, VT, USA) and polyvinyl butyral (PVB) solution were dispersed in $17 \mathrm{~g}$ of N-Methyl-2-pyrrolidone (NMP) and sonicated for $30 \mathrm{~min}$. The prepared spinning solution was extruded into deionized water through an outer stainless-steel capillary, and then, the extruded hollow structure was calcined at $350{ }^{\circ} \mathrm{C}$ for $1 \mathrm{~h}$ in an Ar environment to remove PVB from the carbon nanotube media. The pore size, surface area, and conductivity of the CHM were $13.76 \mathrm{~nm}, 77.81 \mathrm{~m}^{2} / \mathrm{g}$, and $57.5 \mathrm{~s} / \mathrm{cm}$, respectively. A polymeric hollow-fiber media (PVDF, Synopex, Hwaseong-si, Korea) was used as a non-conductive hollow-fiber structure for comparison. 


\subsection{Experiments}

The anaerobic reactor volume was $250 \mathrm{~mL}$, while the working volume was $200 \mathrm{~mL}$. A magnetic stirrer stirred the reactors at $150 \mathrm{rpm}$, while the outlet and inlet ports of the feed were attached to the top of the reactor. Furthermore, the gas collector was connected to a gas outlet line. A water bath was used as temperature controller at $37 \pm 2{ }^{\circ} \mathrm{C}$. Seed sludge was inoculated into $100 \mathrm{~mL}$ of the reactor with $100 \mathrm{~mL}$ of deionized water. The initial $\mathrm{pH}$ was adjusted to 7.0 for optimum reactor operation. After the injection, the reactors were flushed with $\mathrm{N}_{2}$ gas for $3 \mathrm{~min}$ to remove the oxygen. Twenty $\mathrm{mL}$ of feedstock was prepared at a concentration of $0.5 \mathrm{~g}$ chemical oxygen demand (COD)/L, with 10 days hydraulic retention time (HRT) and $0.5 \mathrm{~g}$ COD/L/day organic loading rate (OLR). The reactor was operated for 104 days in a sequencing batch mode $(0.5 \mathrm{~h}$ of feeding, $22.5 \mathrm{~h}$ of reaction, and $1.0 \mathrm{~h}$ of settling) to prevent washout of the CHMs. CHM and PHM (1400 mg each) were injected into $\mathrm{R} 1$ and $\mathrm{R} 2$, respectively. The organic loading rate was $0.5 \mathrm{~g} \mathrm{COD} / \mathrm{L} /$ day, while it was increased stepwise to $4 \mathrm{~g} \mathrm{COD} / \mathrm{L}$ after stabilizing the performance in each step. On day 24, CHM and PHM were supplemented to R1 and R2, respectively.

\subsection{Sample Analysis}

Total suspended solids (TSS), volatile suspended solids (VSS), and alkalinity were analyzed following the Standard Methods for the Examination of Water and Wastewater (APHA, 1998) [17]. Soluble COD was determined using a kit (Humas, Daejeon, Korea) after particles were filtered using $0.45 \mu \mathrm{m}$ PVDF filters (Advantec, Tokyo, USA). Biogas volume was monitored every $24 \mathrm{~h}$. A gas chromatograph analyzed the biogas composition with a thermal conductivity detector (GC-TCD 580, Gow-Mac series, Bethlehem, USA). A stainless steel column packed with molecular sieve ( $80 / 100$ mesh) was used, and nitrogen gas served as the mobile phase. The injector, detector, and column temperatures were 60,80 , and $80^{\circ} \mathrm{C}$, respectively. High-performance liquid chromatography (HPLC, Shimadzu Scientific instruments, MD) was used for the analysis of organic acids with an ultraviolet $(210 \mathrm{~nm})$ detector (SPD-10A, Shimadzu) and Aminex HPX-87H column $300 \mathrm{~mm} \times 7.8 \mathrm{~mm}$ (Bio-Rad, California, USA). Microorganisms attached to CHM or PHM were observed via scanning electron microscopy (SEM) and confocal laser scanning microscopy (CLSM) (Carl Zeiss, Jena, Germany).

\subsection{Microbial Community Analysis}

DNA samples were extracted from R1, R2, and seed sludge using an Ultraclean soil DNA kit and were subsequently purified using an Ultraclean Microbial DNA Isolation Kit (Mo Bio Laboratory Inc., Carlsbad, CA, USA) according to the manufacturer's instructions. After DNA extraction and purification, the variable region (V3-V4) of the 16S rRNA gene was amplified using universal primer sets 519F (5'-CCTACGGGNGGCWGCAG-3') and 806R (5'-GACTACHVGGGTATCTAATCC-3'). According to the manufacturer's instructions from a commercial sequencing facility, high-throughput sequencing was performed using an Illumina MiSeq platform (Illumina, San Diego, CA, USA) (Macrogen, Seoul, Korea). The raw paired-end reads from Illumina Miseq were subsequently analyzed with the software QIIME for pre-processing (quality-adjustment, barcode split), identification of operational taxonomic units (OTUs), community diversity indices (e.g., CHAO1, Shannon, and Simpson), and taxonomic assignment.

\section{Results and Discussion}

\subsection{Effect of CHM on AD Performance}

Figure 1 shows the daily variation of the $\mathrm{CH}_{4}$ production rate (MPR) and COD removal efficiency of R1 and R2. As the initial OLR was $0.5 \mathrm{~g}$ COD/L/day, an MPR of $135 \pm 10 \mathrm{~mL} / \mathrm{L} /$ day in both R1 and R2 was detected; however, it subsequently dropped and stabilized at $70 \pm 6 \mathrm{~mL} / \mathrm{L} /$ day with approximately $63 \%$ COD removal efficiency beyond that point. This was mainly due to the excess $\mathrm{CH}_{4}$ being temporarily produced from leftover COD in the seed sludge during the first period (days 1-11). As the OLR 
increased to $1 \mathrm{~g} \mathrm{COD/L/day} \mathrm{(days} \mathrm{12-24),} \mathrm{the} \mathrm{MPR} \mathrm{of} \mathrm{both} \mathrm{reactors} \mathrm{increased,} \mathrm{reaching}$ $137 \pm 6 \mathrm{~mL} / \mathrm{L} /$ day, and the average COD removal efficiency gradually increased to $72 \%$ in both reactors.

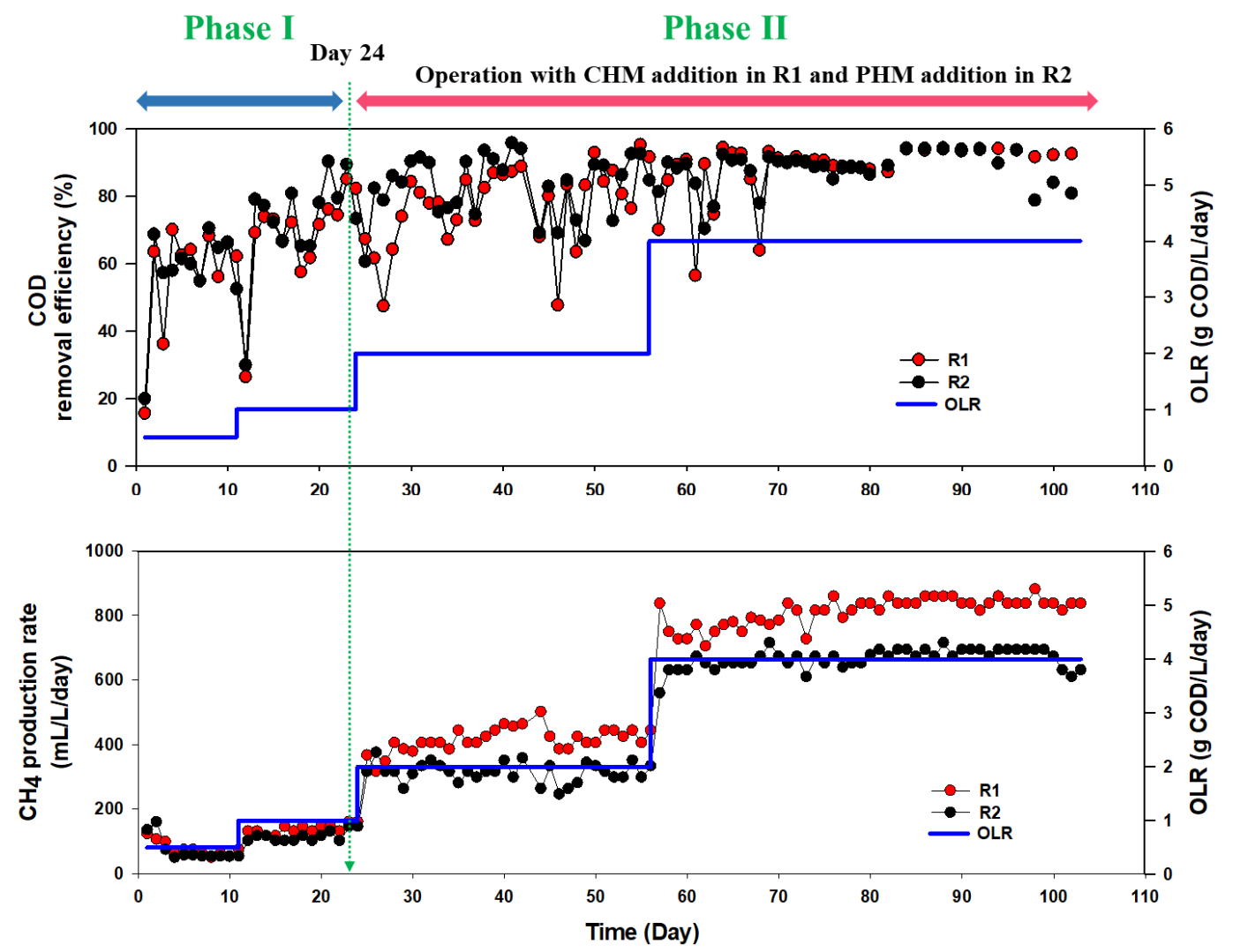

Figure 1. Daily variation of chemical oxygen demand (COD) removal efficiency and $\mathrm{CH}_{4}$ production rate in $\mathrm{R} 1$ and $\mathrm{R} 2$ at various organic loading rates.

On day 24, CHM and PHM were supplemented to R1 and R2, respectively, and OLR further increased to $2 \mathrm{~g}$ COD/L/day. In both reactors, COD removal efficiency was not significantly different, while it was found that $\mathrm{CHM}$ addition to R1 led to a gradual MPR increase, reaching 30\% higher MPR ( $426 \pm 39 \mathrm{~mL} / \mathrm{L} /$ day) compared to R2 after PHM addition (321 $\pm 50 \mathrm{~mL} / \mathrm{L} /$ day). Organic acids remained below $183 \mathrm{mg}$ COD/L in both reactors, attributed mainly to the acetate $(77-79 \%)$ and lactate $(21-23 \%)$ in both reactors (Figure 2). Bicarbonate alkalinity ( $>5000 \mathrm{mg} \mathrm{CaCO} / \mathrm{L}$ ) was high enough to prevent significant $\mathrm{pH}$ fluctuations, resulting in $\mathrm{pH}$ of approximately 7.2-7.4 in both reactors. The positive effect of CHM on AD increased with the increase in OLR to $4 \mathrm{~g} / \mathrm{L} /$ day (days 59-104). The MPR was $839 \pm 15 \mathrm{~mL} / \mathrm{L} /$ day in $\mathrm{R} 1$ and $675 \pm 24 \mathrm{~mL} / \mathrm{L} /$ day in R2. Under these conditions, the $\mathrm{CH}_{4}$ content in biogas was $68 \%$ in $\mathrm{R} 1$ and $60 \%$ in $\mathrm{R} 2$. A gradual reduction of total organic acid with no acetic acid was detected in the effluent of R1, indicating that electrical advance stimulates methanogen conversion from acetate to methane [18]. Meanwhile, the total organic acid content of R2 was the same as that corresponding to an OLR of $2 \mathrm{~g}$ COD/L/day. 


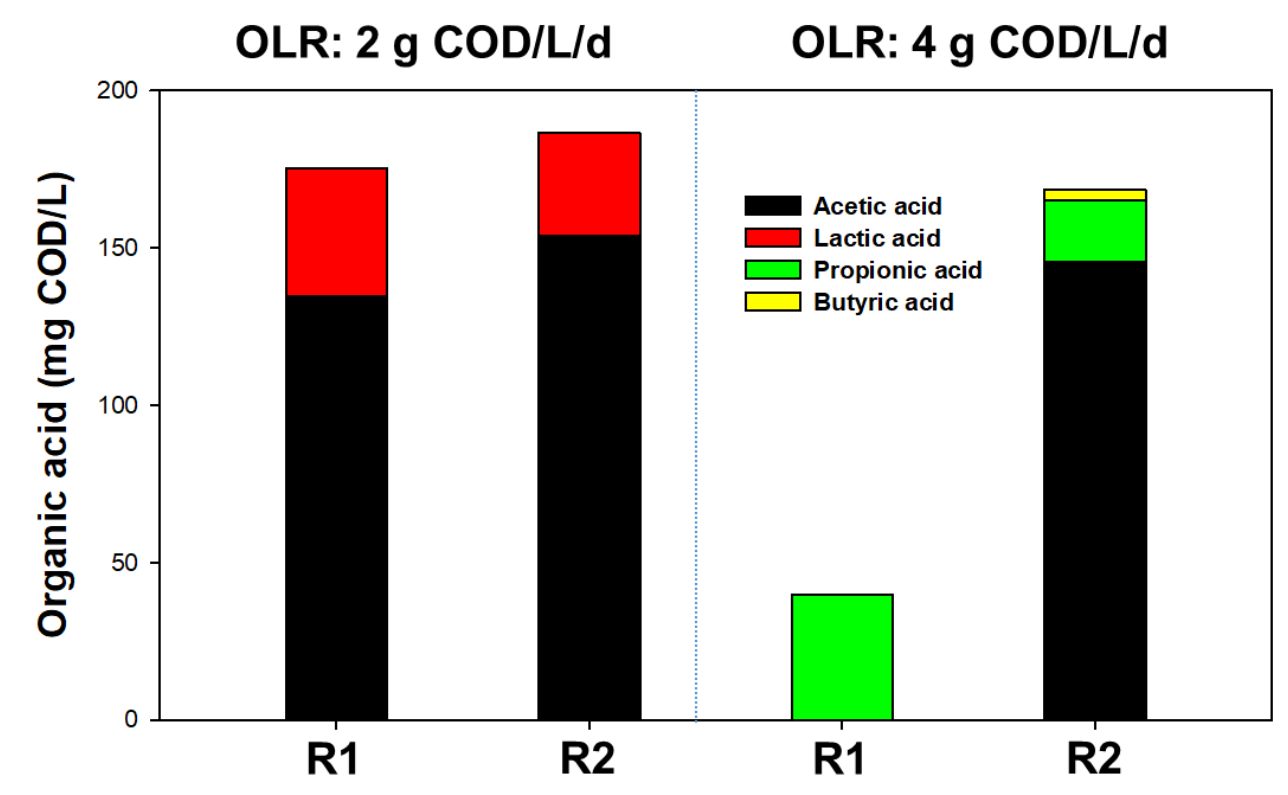

Figure 2. The performance of the organic acid at the steady-state of the reactor with polymeric hollow-fiber media (PHM) and carbon-nanotube hollow-fiber media (CHM).

\subsection{Change in Taxonomic Distribution of the Microorganisms}

To reveal the changes in the $\mathrm{AD}$ microbiome as a result of performance enhancement by CHM (R1) and PHM (R2) addition, mixed liquor samples from seed sludge (day 0 ) and samples at day 90 (R1 and R2) were analyzed via NGS. Log-shaped rarefaction curves of three samples at a similarity of $97 \%$ indicate that the sequences were reliable (data not shown). A total of 166,492 high-quality sequence reads were generated and classified into 358 operational taxonomic units (OTUs), as shown in Table 1. The Shannon index and CHAO1 provide species richness and evenness among all microbial communities [19]. The diversity and richness of both R1 and R2 were lower than those of seed sludge.

Table 1. Analytical results of the microorganism gene libraries obtained from NGS.

\begin{tabular}{ccccc}
\hline Sample & Read Count & OTUs & Chao1 & Shannon \\
\hline Seed sludge & 45,917 & 158 & 158.75 & 3.69 \\
R1 & 58,396 & 103 & 108.83 & 2.30 \\
R2 & 62,178 & 97 & 109.21 & 2.12 \\
\hline
\end{tabular}

The kingdom, class, and genus levels of relative microbial abundance were categorized, and minorities of OTUs (i.e., $<1 \%$ of relative abundance) in the samples were classified as "Others."

As shown in Figure 3a, a gradual increase in OTUs associated with archaea in R1 and $\mathrm{R} 2$ was detected (18.8\% at R1 and $25.4 \%$ at $\mathrm{R} 2)$, and the archaea/bacteria (A/B) ratio was 0.23 (R1) and 0.34 (R2). Meanwhile, the abundance of archaea in the seed sludge was only $5.2 \%$, corresponding to an $\mathrm{A} / \mathrm{B}$ ratio of 0.05 . This result indicates that the archaeal community was developed in both reactors. Regueiro et al. [20] reported that the quantitative percentage of $\mathrm{A} / \mathrm{B}$ ratio in $\mathrm{AD}$ varies from to 0.1-0.7. In addition, given that higher MPR in R1 compared to R2 was associated with lower A/B ratio, the effect of CHM on the syntrophic metabolic pathway associated with DIET in R1 may be positive. 


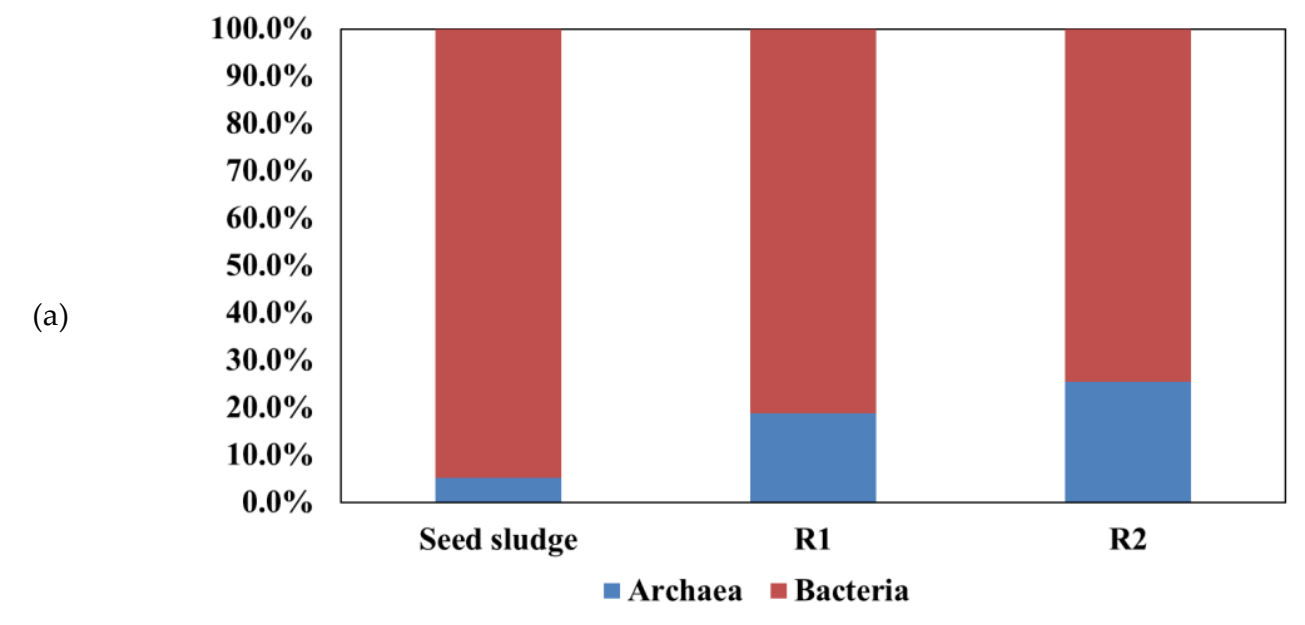

(b)
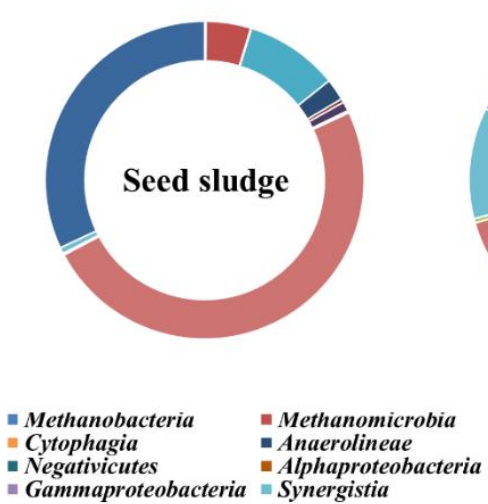
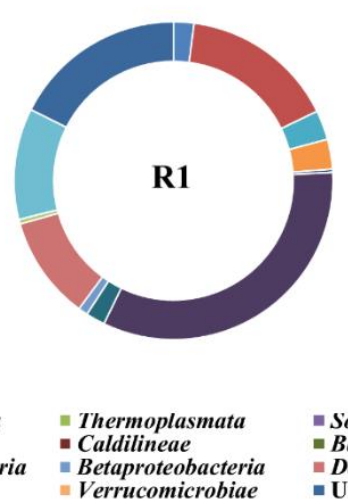
Vetaproteobacteria

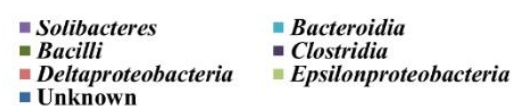
Clostridia Epsilonproteobacteria

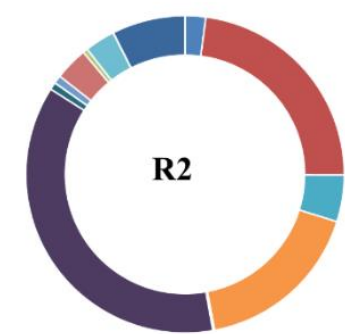

- Unknown

Figure 3. Relative abundances of microorganisms of seed sludge, R1 (with CHM), and R2 (with PHM) at (a) kingdom level and (b) class level (Seed sludge: the sample was taken from the seed sludge; R1 and R2: the samples were taken at the end of operation).

The distribution of microbial abundance at the class level illustrated in Figure $3 b$ shows that the predominant microbial community in the seed sludge was Deltaproteobacteria $(49.2 \%)$ and Bacteroides (9.5\%). However, decreased amounts of Deltaproteobacteria were observed, accounting for $10.5 \%$ and $3.4 \%$ in R1 and R2, respectively, while increased abundance of Clostridia and Methanomicrobia was found in both R1 (33.0\% and 15.7\%) and R2 (36.8\% and 23.0\%). Clostridia are among the most frequently observed acid-producing bacteria, and Methanomicrobia are known as $\mathrm{CH}_{4}$ producing archaea [21,22]. Hu et al. [23] verified that these two types of microorganisms promote synergistic $\mathrm{CH}_{4}$ production through carbohydrate degradation, production of organic acids and $\mathrm{H}_{2}$, and methanogenesis. Other class members, including Synergistia (11.3\% in R1) and Cytophagia (17.2\% in R2), were also observed with high abundance in both R1 and R2.

The distributions of the microbiome at the genus level are shown in Figure 4. Syntrophobacter $(44.8 \%)$ was found to be predominant in the seed sludge, followed by Thermodesulfovibrio (20.4\%), Methanosaeta (4.4\%), Paludibacter (4.1\%), Marinilabilia (3.6\%), Geobacter $(2.8 \%)$, and Levilinea $(1.5 \%)$. Syntrophobacter and Thermodesulfovibrio are known to syntrophically oxidize organic acids and can induce IET to provide $\mathrm{H}_{2}$ to methanogens [10]; however, their abundance decreased as the operation progressed while giving way to newly emerged bacterial microbiomes in both R1 and R2. Lutispora and Methanosaeta became the main members, whose total amount accounted for $47.1 \%$ and $57.7 \%$ in R1 and R2, respectively. Other genera, including Aminiphilus, Pelobacter, Geobacter, Parapedobacter, and Methanobrevibacter, also became more abundant in both R1 and R2. 


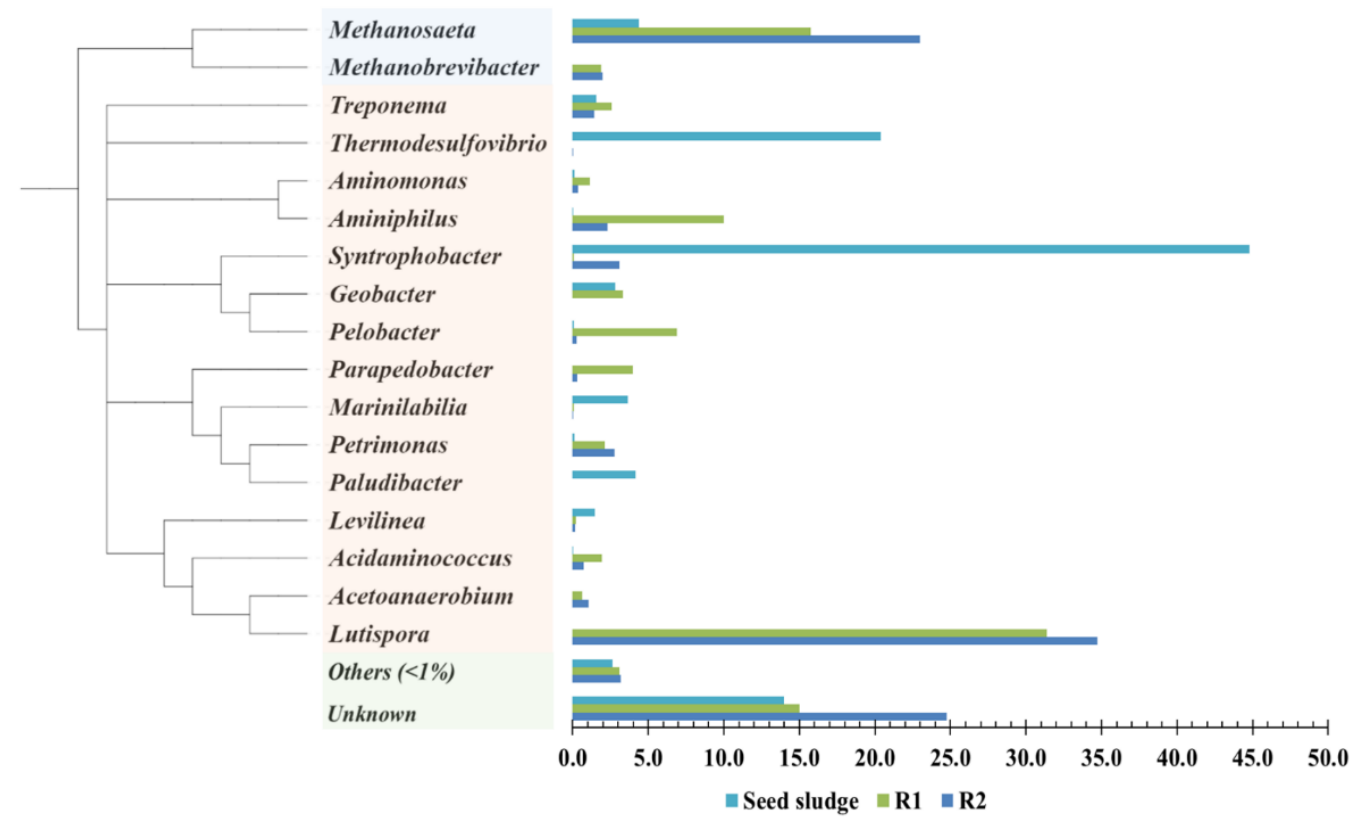

Figure 4. The relative abundances of microorganisms of seed sludge, R1 (with CHM), and R2 (with PHM) at genus level (Seed sludge: the sample was taken from the seed sludge; R1 and R2: the samples were taken at the end of operation). Genera with less than $1 \%$ abundances were classified into others.

Regarding the influence of $\mathrm{CHM}$ in $\mathrm{AD}$ (R1 vs. R2), a different dominant microbiome was a crucial finding. The abundances of Aminiphilus, Pelobacter, and Geobacter were significantly higher in R1 than in R2, accounting for $10.0 \%, 6.9 \%$, and $3.3 \%$ in R1 and $2.3 \%, 0.3 \%$, and $0.0 \%$ in R2, respectively. Pelobacter and Geobacter seemed to be key microorganisms for DIET in R1. These are known as electroactive bacteria and have often been observed in the DIET system in AD [24,25]. Pelobacter, a syntrophic bacterium that oxidizes ethanol to acetic acid, is likely to promote DIET in the presence of CHM in R1, thereby enhancing MPR with a high abundance of Methanosaeta (15.7\%) [26]. Methanosaeta is a well-known electron-accepting microorganism that can directly convert $\mathrm{CO}_{2}$ to $\mathrm{CH}_{4}$ using the DIET pathway [27]. Increased abundance of Aminiphilus in R1 was related to propionate oxidizing syntrophic association [28]. This result is in agreement with a previous study showing that propionate-oxidizing bacteria are also likely to be involved in DIET [6].

\subsection{Effect of CHM on Direct Interspecies Electron Transfer}

Many studies have employed various types of conductive materials to stimulate methanogenesis via DIET in AD $[6,14,27,29]$. They demonstrated that conductive materials could be the conduit for electron transfer between microorganisms that replaced the IET pathway. DIET has the advantage of faster electron transfer than IET, which is the $\mathrm{H}_{2}$ diffusion pathway. DIET pathway has been established with various conductive materials. Magnetite was proven to promote the growth of syntrophic bacteria [12]. In addition, the vast majority of studies have used carbon materials as a conductive material to promote DIET in AD. It has been revealed that the addition of activated carbon stimulated DIET in the AD of various types of substrates [13]. Zhao et al. (2016) also observed that the biogas production rate increased in the presence of biochar [10]. However, the addition of those materials into $\mathrm{AD}$ is not economically feasible because those may easily wash out during long-term continuous operation. In contrast, $\mathrm{CHM}$ can provide a practical solution to this challenge. In addition, the large surface area $\left(77.81 \mathrm{~m}^{2} / \mathrm{g}\right)$ of CHM was beneficial for enriching electroactive bacteria and methanogens on the surface to promote DIET. However, previous studies have reported that carbon nanotubes (CNTs) have a physical cytotoxic effect on microbes, which can affect microbial community activity and diversity. This toxic effect was determined by the physicochemical characteristics of CNTs (e.g., single-wall 
or multi-wall) $[30,31]$. In order to verify the toxic effect of $\mathrm{CHM}$ on the microbiome in R1, CLSM was analyzed. Figure 5a shows several living cells of microorganisms (blue color) densely attached to the surface of the $\mathrm{CHM}$, indicating lack of noticeable microbial toxic effect. In addition, as shown in Figure 5b, microbiomes with pili were attached to the $\mathrm{CHM}$ surface, indicating that the CHM played a key role as electrical conduits facilitating electronic connections between microbial cells, leading to a higher MPR in R1 compared to $\mathrm{R} 2$, where non-conductive hollow fiber type media were added.

(a)

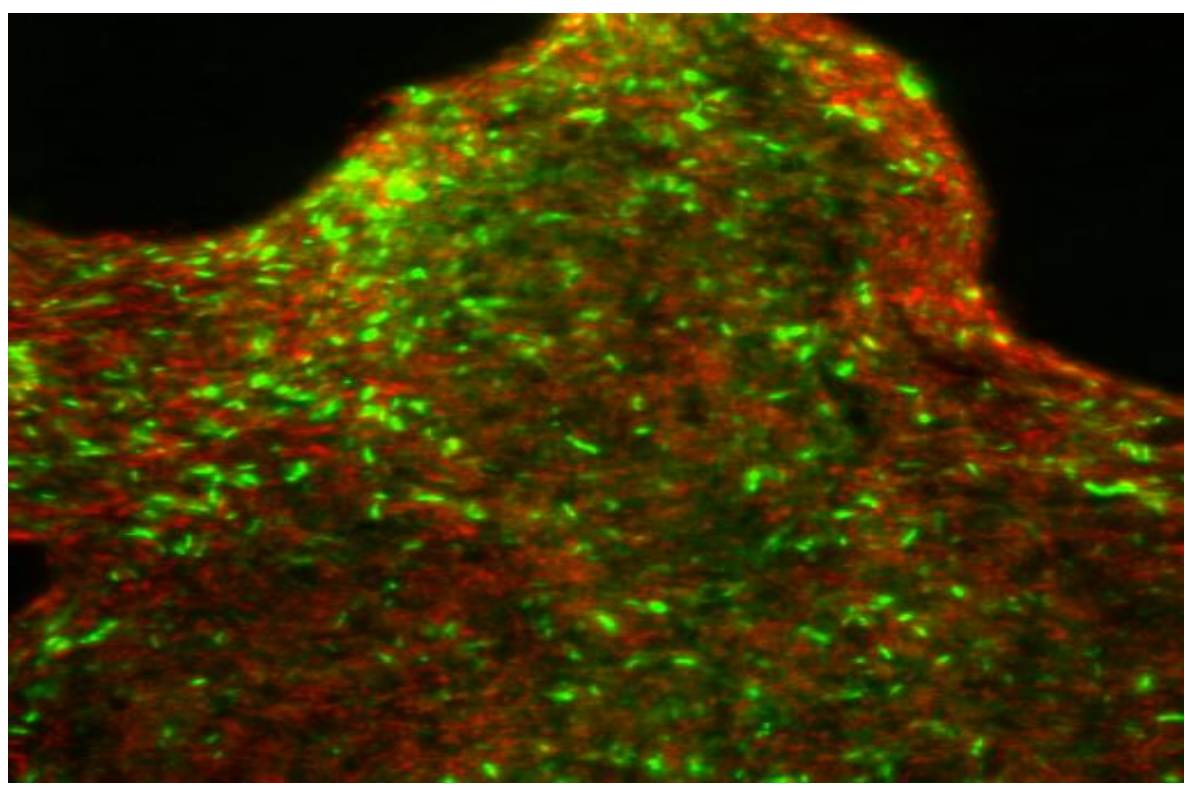

(b)

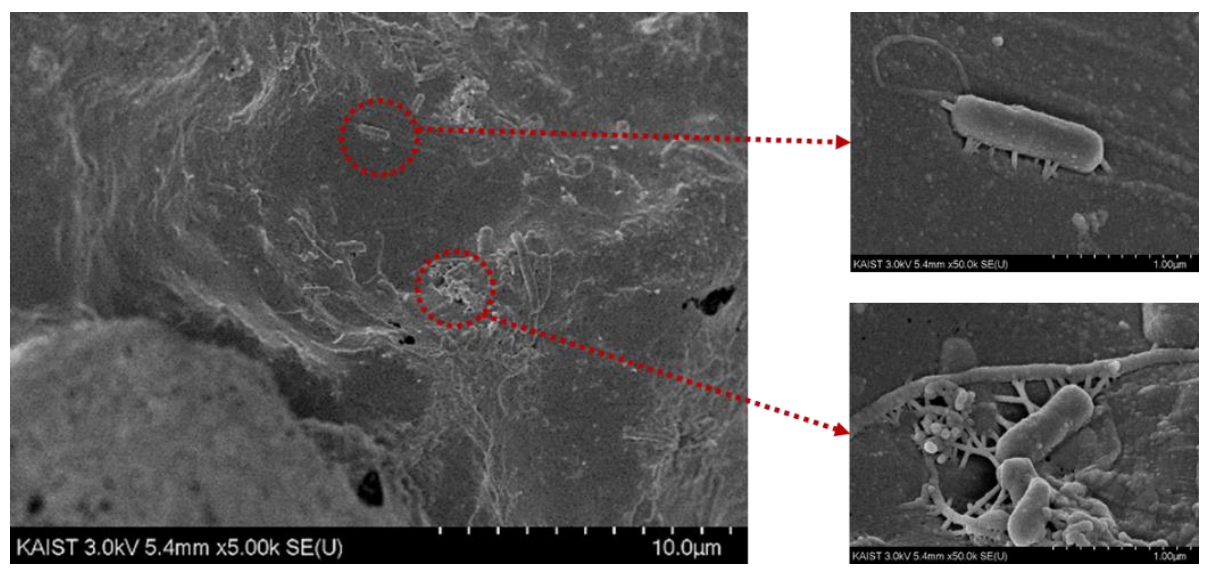

Figure 5. (a) The confocal laser scanning microscopy (CLSM) and (b) scanning electron microscopy (SEM)images of biofilm attached to the surface of CHM taken from R1 at the end of operation.

\section{Conclusions}

In this study, a higher $\mathrm{CH}_{4}$ production rate associated with lower archaea/bacteria ratio showed that carbon-nanotube hollow-fiber media ( $\mathrm{CHM}$ ) have a positive effect on the metabolic pathway of anaerobic digestion (AD). This was further verified by the changed microbiomes (Pelobacter, Geobacter, and Methanosaeta) associated with lower concentration of organic acids, making syntrophic metabolism thermodynamically exergonic. SEM and CLSM images revealed the dense attachment of microorganisms on the CHM surface with pili. This study provides evidence of direct interspecies electron transfer (DIET) and utilization of $\mathrm{CHM}$ under anaerobic conditions to enhance $\mathrm{CH}_{4}$ production and may elucidate the microbial DIET of AD. 
Author Contributions: Formal analysis and writing—original draft preparation, S.Y.; investigation, S.H.; writing-review and editing and visualization, Y.-M.Y.; supervision, review, and edit, S.K. All authors have read and agreed to the published version of the manuscript.

Funding: We acknowledge the financial support of the National Research Foundation under "Next Generation Carbon Upcycling Project" (Project No. 2017M1A2A2042517) of the Ministry of Science and ICT, Republic of Korea. This research was also supported by the Korea Ministry of Environment as part of the Waste to Energy-Recycling Human Resource Development Project (YL-WE-19-002).

Institutional Review Board Statement: Not applicable.

Informed Consent Statement: Not applicable.

Data Availability Statement: Not applicable.

Conflicts of Interest: The authors declare no conflict of interest.

\begin{tabular}{lll} 
Abbreviations & & \\
\hline Full Name & Abbreviation & Unit \\
\hline Anaerobic digestion & AD & \\
Carbon-nanotube hollow-fiber media & CHM & mg COD/L \\
$\begin{array}{l}\text { Chemical oxygen demand } \\
\text { Confocal laser scanning microscopy }\end{array}$ & COD & \\
Direct interspecies electron transfer & DIET & \\
interspecies electron transfer & IET & \\
Methane production rate & MPR & \\
Operational taxonomic units & OTUs & g COD/L/day \\
Organic loading rate & OLR & \\
Polymeric hollow-fiber media & PHM & \\
\hline
\end{tabular}

\section{References}

1. World Biogas Association. Available online: https://www.worldbiogasassociation.org/wp-content/uploads/2019/07/WBAglobalreport-56ppa4_digital.pdf (accessed on 27 December 2020).

2. Zhang, P.; Yan, F.; Du, C. A comprehensive analysis of energy management strategies for hybrid electric vehicles based on bibliometrics. Renew. Sust. Energ. Rev. 2015, 48, 88-104. [CrossRef]

3. Available online: https://www.fortunebusinessinsights.com/industry-reports/biogas-market-100910 (accessed on 27 December 2020).

4. Rajagopal, R.; Massé, D.I.; Singh, G. A critical review on inhibition of anaerobic digestion process by excess ammonia. Bioresour. Technol. 2013, 143, 632-641. [CrossRef] [PubMed]

5. Sposob, M.; Moon, H.S.; Lee, D.; Kim, T.H.; Yun, Y.M. Comprehensive analysis of the microbial communities and operational parameters of two full-scale anaerobic digestion plants treating food waste in South Korea: Seasonal variation and effect of ammonia. J. Hazard. Mater. 2020, 398, 122975. [CrossRef]

6. Baek, G.; Jung, H.; Kim, J.; Lee, C. A long-term study on the effect of magnetite supplementation in continuous anaerobic digestion of dairy effluent-magnetic separation and recycling of magnetite. Bioresour. Technol. 2017, 241, 830-840. [CrossRef]

7. Baek, G.; Shi, L.; Rossi, R.; Logan, B.E. The effect of high applied voltages on bioanodes of microbial electrolysis cells in the presence of chlorides. Chem. Eng. J. 2021, 405, 126742. [CrossRef]

8. Chen, S.; Rotaru, A.-E.; Shrestha, P.M.; Malvankar, N.S.; Liu, F.; Fan, W.; Nevin, K.P.; Lovley, D.R. Promoting Interspecies Electron Transfer with Biochar. Sci. Rep. 2014, 5019. [CrossRef]

9. Summers, Z.M.; Fogarty, H.E.; Leang, C.; Franks, A.E.; Malvankar, N.S.; Lovley, D.R. Direct Exchange of Electrons Within Aggregates of an Evolved Syntrophic Coculture of Anaerobic Bacteria. Science 2010, 330, 1413-1415. [CrossRef]

10. Zhao, Z.; Zhang, Y.; Holmes, D.E.; Dang, Y.; Woodard, T.L.; Nevin, K.P.; Lovley, D.R. Potential enhancement of direct interspecies electron transfer for syntrophic metabolism of propionate and butyrate with biochar in up-flow anaerobic sludge blanket reactors. Bioresour. Technol. 2016, 209, 148-156. [CrossRef]

11. Yee, M.O.; Rotaru, A.E. Extracellular electron uptake in Methanosarcinales is independent of multiheme c-type cytochromes. Sci. Rep. 2020, 10, 1-12. [CrossRef]

12. Kato, S.; Hashimoto, K.; Watanabe, K. Microbial interspecies electron transfer via electric currents through conductive minerals. Proc. Natl. Acad. Sci. USA 2012, 109, 10042-10046. [CrossRef] [PubMed]

13. Lee, J.-Y.; Lee, S.-H.; Park, H.-D. Enrichment of specific electroactive microorganisms and enhancement of methane production by adding granular activated carbon in anaerobic reactors. Bioresour. Technol. 2016, 205, 205-212. [CrossRef] 
14. Lekawa-Raus, A.; Patmore, J.; Kurzepa, L.; Bulmer, J.; Koziol, K. Electrical Properties of Carbon Nanotube Based Fibers and Their Future Use in Electrical Wiring. Adv. Funct. Mater. 2014, 24, 3661-3682. [CrossRef]

15. Wei, G.; Yu, H.; Quan, X.; Chen, S.; Zhao, H.; Fan, X. Constructing All Carbon Nanotube Hollow Fiber Membranes with Improved Performance in Separation and Antifouling for Water Treatment. Environ. Sci. Technol. 2014, 48, 8062-8068. [CrossRef]

16. Matsumoto, K.; Uejima, H.; Iwasaki, T.; Sano, Y.; Sumino, H. Studies on regenerated protein fibers. III. Production of regenerated silk fibroin fiber by the self-dialyzing wet spinning method. J. Appl. Polym. Sci. 1996, 60, 503-511. [CrossRef]

17. Gilcreas, F.W. Standard methods for the examination of water and waste water. Am. J. Public Health Nation's Health 1966, 56, 387-388. [CrossRef]

18. Viggi, C.C.; Rossetti, S.; Fazi, S.; Paiano, P.; Majone, M.; Aulenta, F. Magnetite Particles Triggering a Faster and More Robust Syntrophic Pathway of Methanogenic Propionate Degradation. Environ. Sci. Technol. 2014, 48, 7536-7543. [CrossRef]

19. Yun, Y.M.; Sung, S.; Shin, H.S.; Han, J.I.; Kim, H.W.; Kim, D.H. Producing desulfurized biogas through removal of sulfate in the first-stage of a two-stage anaerobic digestion. Biotechnol. Bioeng. 2017, 114, 970-979. [CrossRef]

20. Regueiro, L.; Veiga, P.; Figueroa, M.; Alonso-Gutierrez, J.; Stams, A.J.M.; Lema, J.M.; Carballa, M. Relationship between microbial activity and microbial community structure in six full-scale anaerobic digesters. Microbiol. Res. 2012, 167, 581-589. [CrossRef] [PubMed]

21. Hawkes, F.R.; Dinsdale, R.; Hawkes, D.L.; Hussy, I. Sustainable fermentative hydrogen production: Challenges for process optimisation. Int. J. Hydrog. Energy 2002, 27, 1339-1347. [CrossRef]

22. Xia, Y.; Massé, D.I.; McAllister, T.A.; Kong, Y.; Seviour, R.; Beaulieu, C. Identity and diversity of archaeal communities during anaerobic co-digestion of chicken feathers and other animal wastes. Bioresour. Technol. 2012, 110, 111-119. [CrossRef] [PubMed]

23. Hu, X.; Du, H.; Ren, C.; Xu, Y. Illuminating Anaerobic Microbial Community and Cooccurrence Patterns across a Quality Gradient in Chinese Liquor Fermentation Pit Muds. Appl. Environ. Microbiol. 2016, 82, 2506-2515. [CrossRef]

24. Ledezma, P.; Lu, Y.; Freguia, S. Electroactive haloalkaliphiles exhibit exceptional tolerance to free ammonia. FEMS Microbiol. Lett. 2017, 365, fnx260. [CrossRef] [PubMed]

25. Moscoviz, R.; de Fouchécour, F.; Santa-Catalina, G.; Bernet, N.; Trably, E. Cooperative growth of Geobacter sulfurreducens and Clostridium pasteurianum with subsequent metabolic shift in glycerol fermentation. Sci. Rep. 2017, 7, 44334. [CrossRef] [PubMed]

26. Salvador, A.F.; Martins, G.; Melle-Franco, M.; Serpa, R.; Stams, A.J.M.; Cavaleiro, A.J.; Pereira, M.A.; Alves, M.M. Carbon nanotubes accelerate methane production in pure cultures of methanogens and in a syntrophic coculture. Environ. Microbiol. 2017, 19, 2727-2739. [CrossRef]

27. Dang, Y.; Holmes, D.E.; Zhao, Z.; Woodard, T.L.; Zhang, Y.; Sun, D.; Wang, L.-Y.; Nevin, K.P.; Lovley, D.R. Enhancing anaerobic digestion of complex organic waste with carbon-based conductive materials. Bioresour. Technol. 2016, 220, 516-522. [CrossRef] [PubMed]

28. Diaz, C.; Baena, S.; Fardeau, M.-L.; Patel, B.K.C. Aminiphilus circumscriptus gen. nov., sp. nov., an anaerobic amino-aciddegrading bacterium from an upflow anaerobic sludge reactor. Int. J. Syst. Evol. Microbiol. 2007, 57, 1914-1918. [CrossRef]

29. Li, Y.; Zhang, Y.; Yang, Y.; Quan, X.; Zhao, Z. Potentially direct interspecies electron transfer of methanogenesis for syntrophic metabolism under sulfate reducing conditions with stainless steel. Bioresour. Technol. 2017, 234, 303-309. [CrossRef]

30. Liu, F.; Rotaru, A.E.; Shrestha, P.M.; Malvankar, N.S.; Nevin, K.P.; Lovley, D.R. Promoting direct interspecies electron transfer with activated carbon. Energy Environ. Sci. 2012, 5, 8982-8989. [CrossRef]

31. Kang, S.; Mauter, M.S.; Elimelech, M. Physicochemical Determinants of Multiwalled Carbon Nanotube Bacterial Cytotoxicity. Environ. Sci. Technol. 2008, 42, 7528-7534. [CrossRef] 